OPEN ACCESS

Edited by:

Xin Wang,

University of Manchester,

United Kingdom

Reviewed by:

Jason Hellmann,

University of Louisville, United States

Yuhuang Li,

Technical University of Munich,

Germany

*Correspondence:

Huifang Liu

Lhf_404@163.com

Fengling Chen

Chenfl1101@126.com

Specialty section:

This article was submitted to

Cardiovascular and Smooth Muscle

Pharmacology,

a section of the journal

Frontiers in Pharmacology

Received: 30 May 2020 Accepted: 22 September 2020

Published: 26 November 2020

Citation:

Ma X, Liu H and Chen F (2020)

Functioning of Long Noncoding RNAs

Expressed in Macrophage in the

Development of Atherosclerosis.

Front. Pharmacol. 11:567582.

doi: $10.3389 /$ fphar.2020.567582

\section{Functioning of Long Noncoding RNAs Expressed in Macrophage in the Development of Atherosclerosis}

\author{
Xirui Ma, Huifang Liu* and Fengling Chen *
}

Department of Endocrinology and Metabolism, Shanghai Ninth People's Hospital, Shanghai Jiao Tong University School of Medicine, Shanghai, China

Chronic inflammation is part of the pathological process during atherosclerosis (AS). Due to the abundance of monocytes/macrophages within the arterial plaque, monocytes/ macrophages have become a critical cellular target in AS studies. In recent decades, a number of long noncoding RNAs (IncRNAs) have been found to exert regulatory roles on the macrophage metabolism and macrophage plasticity, consequently promoting or suppressing atherosclerotic inflammation. In this review, we provide a comprehensive overview of IncRNAs in macrophage biology, highlighting the potential role of IncRNAs in AS based on recent findings, with the aim to identify disease biomarkers and future therapeutic interventions for AS.

Keywords: long noncoding RNA, atherosclerosis, macrophage, kappa B, foam cell macrophage

\section{INTRODUCTION}

Atherosclerosis (AS) is a multifaceted chronic inflammatory disease characterized by the formation of atherosclerotic plaques predominantly at branch points of arteries and bifurcations due to the disturbed laminar flow at these sites (Shapouri-Moghaddam et al., 2018). Atherosclerotic plaques consist of lipids, foam cells, calcified sites, and necrotic cores (Donaldson et al., 2018; Moore et al., 2013; Shapouri-Moghaddam et al., 2018; Tabas and Bornfeldt, 2016). Monocytes and macrophages are dynamically involved in the initiation and development of AS and ultimately contribute to plaque rupture. An altered metabolism dictates macrophage activities and subsequent AS progression (Koelwyn et al., 2018).

During early atherogenic stages, apolipoprotein B-lipoproteins accumulated in the intima initiate an early inflammatory response and formation of fatty streak lesions (Williams and Tabas, 1995; Moore and Tabas, 2011; Liu et al., 2014). The inflammatory response progresses through various modifications in the endothelium, such as oxidation (causing altered expression of adhesion molecules and elevating secretion of chemokines) (Moore and Tabas, 2011). Activated endothelial cells produce monocyte chemoattractant protein-1 (MCP-1). On monocytes, MCP-1 can interact with cognate chemokine receptors and promote monocyte migration in a specific direction (Moore and Tabas, 2011). Later, the recruited monocytes are tethered and roll along the endothelium. The interaction between P-selectin glycoprotein ligand-1 molecules on monocytes and endothelial selectins further triggers firm adhesions (Mestas and Ley, 2008). After entering the intima, monocytes gradually differentiate into macrophages and internalize native and modified lipoproteins (Johnson and Newby, 2009; Paulson et al., 2010). Atherosclerosis is a nonresolving inflammatory condition characterized by monocytes continually entering the intima and lesion plaques and constantly differentiating into macrophages (Moore and Tabas, 2011). 
Lipid uptake, cholesterol esterification, and efflux are three distinct processes of a normal cholesterol metabolism in macrophages (Chistiakov et al., 2017). Disturbances of the cholesterol metabolism are a key contributor to AS, resulting in the accumulation of lipids in macrophages and the formation of "foam cells" (Crowther, 2005; Maguire et al., 2019). In the early plaque, uptake of modified low-density lipoprotein (LDL) (Kunjathoor et al., 2002), phagocytosis of matrix-retained LPs, and pinocytosis of fluid native LDL contribute to foam cell formation (Tabas et al., 1993; Kruth et al., 2005; Moore and Tabas, 2011). Key scavenger receptors such as the CD36, SR-A class, and lectin-like oxLDL receptor-1 play regulatory roles on cholesterol uptake and the formation of foam cells (Moore and Freeman, uhu2006).

In advanced AS lesions, macrophage apoptosis, incomplete clearance, and defective phagocytosis of apoptotic macrophages give rise to necrotic cores, which exacerbate inflammation, incite thrombosis, and increase inner stress on the fibrous plaques (Virmani et al., 2002; Tabas, 2010). Notably, thinning of the fibrous cap and necrotic core size increments are critical features of vulnerable plaques. The sites on the shoulder of necrotic cores are vulnerable to rupture. Functions and biological mechanisms of all lncRNAs we discussed below are summarized in Table $\mathbf{1 .}$

\section{LONG NONCODING RNAS}

Long noncoding RNAs (lncRNAs) are defined as a large class of non-protein-coding transcripts. They consist of more than 200 nucleotides in length. Knowledge on the biological function of lncRNAs has been expanding with new publications in the fields of epigenetic activity regulation (McHugh et al., 2015), cis(Engreitz et al., 2016) and trans- (Atianand et al., 2016) gene transcription regulations, protein translation (Carrieri et al., 2012), RNA (Hansen et al., 2013) or protein "sponging," (Tichon et al., 2016), and nuclear/cytoplasmic "shuttling" (Yap et al., 2018; Maguire and Xiao, 2020).

In accordance with the positional association between lncRNAs and protein-coding genes (Gao et al., 2020), the lncRNAs can be classified as exonic sense, anti-sense, intronic sense, bidirectional (enhancer), and intergenic sense classes (Derrien et al., 2012). At the transcriptional level, lncRNAs can also be divided into four models (signals, decoys, guides, or scaffolds) to regulate gene expression (Chang, 2011; Mathy and Chen, 2017; Wang and Chang, 2011).

\section{LONG NONCODING RNAS IN MACROPHAGE DIFFERENTIATION}

Monocyte chemotaxis is triggered by chemokines or cytokines released from cells in damaged tissue or infection areas and stimulates monocytes to migrate to pathologic sites and begin differentiation into macrophages. These macrophages effectively take infections under control and remove dead cells and debris for tissue repair and wound healing. On the other hand, macrophages are involved in the inflammatory tissue damage caused by inflammatory diseases (Moore and Tabas, 2011).
In the development of AS, MCP-1 secreted by endothelial cells is a potent chemokine for monocyte migration involved in the initiation of the inflammatory response (Panee, 2012). MCP-1 attracts monocytes in the circulation, triggering migration via its interaction with the membrane CC chemokine receptor 2 on monocytes. Under normal blood flow conditions, monocytes can firmly adhere to the vascular endothelium through interactions with MCP-1, IL-8, or CXC ligand-8 (Melgarejo et al., 2009, Shapouri-Moghaddam et al., 2018; Moghaddam et al., 2018). After entering the intima, phagocytic monocyte-derived macrophages start to internalize native and modified lipoproteins (Johnson and Newby, 2009; Paulson et al., 2010; Moore and Tabas, 2011).

Long noncoding monocytic RNA (lnc-MC) and miR-199a-5p, both PU.1-regulated noncoding RNAs, work together during human monocyte/macrophage differentiation. The dominant transcription factor PU.1 commits the monocytic lineage during hematopoiesis and promotes the maturation of monocytes/macrophages (Anderson et al., 1998; Lin et al., 2014). PU.1 transcriptionally regulates lnc-MC. Increased expression of lnc-MC reinforces the role of PU.1 by sequestering and soaking upmiR-199a-5p, relieving the suppression on the expression of activin $\mathrm{A}$ receptor type $1 \mathrm{~B}$, an important regulator of monocyte/macrophage differentiation. This suggests that lnc-MC acts as an antagonist of miR-199a-5p and strengthens the role of PU.1 in cell differentiation (Chen et al., 2015).

\section{LONG NONCODING RNAS IN MACROPHAGE PHENOTYPIC SWITCHING}

Plasticity and polarization are hallmarks of macrophages (Wang L. X. et al., 2019). Phenotype switching of macrophages, in response to cues from the local microenvironment, is necessary for a diversity of indispensable functions during host defense responses and tissue repair (Koelwyn et al., 2018). Reciprocal skewing of macrophage polarization is modulated by many intricate factors like the daily dietary intakes and transcriptional factors (Chinetti-Gbaguidi and Staels, 2011). Macrophages can be broadly categorized into two types: M1 and M2 phenotypes. Classically, M1-activated macrophages enhance the production of pro-inflammatory cytokines (TNF, IL-6, IL-1 $\beta$, IL-12, and IL-23 in humans) and lower the secretion of IL-10 (Verreck et al., 2004), whereas M2 macrophages are characterized by their improved endocytic clearance capacity that can protect local tissues from detrimental inflammatory damages and eliminate inflammation (Mantovani et al., 2004; ChinettiGbaguidi and Staels, 2011). Therefore, metabolic reprogramming in macrophages has a direct influence on cell functions and energy homeostasis (Koelwyn et al., 2018). In AS, both macrophage phenotypes are present in fibrous caps of established lesions (Anderson et al., 2002), with a predominance of M1 over M2 in progressing atherosclerotic lesions (Khallou-Laschet et al., 2010; Chinetti-Gbaguidi and Staels, 2011; Khallou et al., 2010). TCONS_00019715 was the first reported lncRNA expressed in human macrophages with 
phenotype switching functions. The expression level of TCONS_00019715 in macrophages was drastically induced by IFN- $\gamma+$ LPS stimulation, and it underwent a strong reduction after IL-4 treatment. Knockdown of TCONS_00019715 reduced the expression of M1 markers in IFN- $\gamma+$ LPS-stimulated macrophages, and it elevated the M2 phenotype markers in IL-4-stimulated ones. PAK1 (p21-activated kinase 1), an important protein-coding gene associated with TCONS_00019715, has been speculated to mediate TCONS_00019715's macrophage polarization effects (Huang Z. et al., 2016). The myocardial infarction-associated transcript 2 (Mirt2) is another lncRNA that has been proved to affect macrophage phenotypic switching. It can block the expression of the M1 polarization and has anti-inflammatory functions through its control of $\mathrm{NF}_{-\kappa} \mathrm{B}$ activation (Du et al., 2017). Detailed information about the function of Mirt2 will be covered in a later section.

\section{LONG NONCODING RNAS IN MACROPHAGE APOPTOSIS}

Macrophage apoptosis occurs during the atherosclerotic plaque development process. Apoptosis in the early stages is protective because it cleans up macrophage foam cells residing inside the plaque lesions (Shapouri-Moghaddam et al., 2018).

LincRNA-p21 has been shown to modulate cell proliferation and apoptosis in AS. In apolipoprotein E-deficient $\left(\mathrm{ApoE}^{-1-}\right)$ mice with atherosclerotic plaques, lincRNA-p21 expression was dramatically reduced at the transcription level. Small interfering RNA-induced lincRNA-p21 inhibition greatly increased the total number of RAW274.7 and HA-VSMC cells. P53 could transcriptionally target lincRNA-p21. In the mouse carotid artery injury model, blockade of lncRNA-p21 dysregulated many p53 downstream targets, leading to neointimal hyperplasia and enhanced cell proliferation with reduced apoptosis (Wu et al., 2014).

Cytoplasmic lncRNA CERNA1 can stabilize atherosclerotic plaques by promoting an important apoptosis inhibitor named apoptosis inhibitor 5 (API5). API5 is capable of inhibiting apoptosis of VSMCs and anti-inflammatory macrophages in apolipoprotein $\mathrm{E}^{-/-}$(Apo $\mathrm{E}^{-/-}$) mice (Lu et al., 2019).

In a most recent study, an lncRNA associated with the progression and intervention of AS named RAPIA was increasingly expressed in advanced atherosclerotic sites and in macrophages. Blockade of RAPIA greatly attenuated the development of advanced AS in $\mathrm{ApoE}^{-/-}$mice (Sun et al., 2020). RAPIA exerted a regulatory role by targeting miR-183$5 p$ in macrophages. miR-183-5p contains two binding sites for RAPIA. As RAPIA binds to miRNA-183-5p, miRNA loses its ability to inhibit proliferation or to promote macrophage apoptosis. Interestingly, suppression of RAPIA has atheroprotective effects in $\mathrm{ApoE}^{-/-}$mice fed with a high-fat diet which is similar to those of atorvastatin on advanced atherosclerotic plaques, by attenuating lipid accumulation, decreasing plaque size, increasing collagen content, and decreasing macrophage accumulation in advanced atherosclerotic plaques. Therefore, repressing RAPIA expression may be an alternative treatment for advanced atherosclerotic lesions, especially in patients resistant or intolerant to statins (Sun et al., 2020).

\section{LONG NONCODING RNAS IN MACROPHAGE PYROPTOSIS}

Pyroptosis is a programmed cell death of macrophages controlled by the NF-кB pathway (Bergsbaken et al., 2009; Sunami et al., 2012; Shen et al., 2014; Sheng et al., 2014). It causes cell lysis. Inflammatory responses can be induced upon cytosolic content release to the extracellular space (Xu et al., 2018). However, this type of cell death, once mislabeled as apoptosis, is attributable to the involvement of caspase 1 (Shi et al., 2017). Pyroptosis can be induced in macrophages in lesions by ox-LDL and cholesterol crystal-triggered increases in NLRP3 inflammasome and caspase 1, leading to AS progression. In advanced atherosclerotic lesions, the formation of necrotic cores and unstable plaques may be attributed to macrophage pyroptosis (Xu et al., 2018).

MALAT1 in diabetic AS has been reported to participate in macrophage pyroptosis after sinapic acid (SA) treatment. Gainand loss-of-function approaches have demonstrated that in normal macrophages, MALAT1 shows a modestly beneficial effect against pyroptosis. Chronic low-dose SA treatment could block the inflammasome activation, macrophage pyroptosis, and the systemic inflammatory response by mediating MALAT1 (Yong et al., 2018).

\section{LONG NONCODING RNAS IN MACROPHAGE DURING ATHEROSCLEROTIC INFLAMMATION}

Many studies have shown that lncRNAs affect the expression profiles of inflammatory pathways in different diseases. For example, in response to LPS stimulation, LIN28B-AS1 (Xie Z. et al., 2019) and Mirt2 (Du et al., 2017) associate with pro- and anti-atherosclerotic inflammation factors in macrophages through NF- $\mathrm{B}$. Mathy's review provided detailed information about lncRNAs' classification and functions in transcriptional control (Mathy and Chen, 2017). In this review, we focused on the functions and effects of individual lncRNAs in the context of atherosclerotic inflammation.

The canonical NF- $\mathrm{B}$ signaling is critical for regulation of innate and adaptive immune responses and is involved in cell proliferation and apoptosis, migration, and invasion (Taniguchi and Karin, 2018). The activation of $N F-\kappa B$ is induced by inflammatory chemokines, notably LPS, TNF- $\alpha$, IL-1, and many toll-like receptors (TLRs) (Qin et al., 2005; Mathy and Chen, 2017). Under inactive conditions, Iк $\mathrm{B} \alpha$ sequesters cytoplasmic p50-p65 dimers, hindering the translocation of p50-p65 dimers to the nucleus. After receiving activating signals, $I_{\kappa} B \alpha$ is phosphorylated by a $I_{\kappa} B$ kinase complex and get degraded into free $\mathrm{NF}-\kappa \mathrm{B}$ dimers. Free $\mathrm{NF}-\kappa \mathrm{B}$ dimers translocate to the nucleus, where they interact with specific 
DNA-binding sites to augment transcription and expression of different genes (Baker and Ghosh, 2010; Hayden and Ghosh, 2014; Mitchell and Carmody, 2018).

A number of studies have mentioned lncRNAs' diverse regulatory roles in inflammatory diseases, including AS, by controlling NF-kB-regulated transcription in both the cytosol and nucleus.

\section{TOLL-LIKE RECEPTOR LIGATION-STIMULATED LONG NONCODING RNAS}

In response to LPS stimulation, lncRNA-Mirt2 (Du et al., 2017), LINC00305, LIN28B-AS1 (Zhang et al., 2017), and MALAT1 (Zhao et al., 2016) show remarkable effects on the progression of AS through NF-кB-dependent mechanisms. LINC00305 is a proinflammatory agent during AS progression. In Zhang's work, LINC00305 in the cytosol interacted with the transmembrane protein lipocalin-1 interacting membrane receptor (LIMR) and promoted the expression of inflammatory genes in human THP-1 cells. Notably, LINC00305 has been associated with LPSstimulated inflammation by targeting the transmembrane receptor LIMR. The inflammation promotor in LPS shock, aryl-hydrocarbon receptor repressor (AHRR), is a binding partner of LIMR (Brandstätter et al., 2016) that tends to enhance NF- $\mathrm{B}$ activity when cotransfected with LIMR. LINC00305-LIMR interaction strengthened LIMR-AHRR binding and promoted AHRR nuclear localization in addition to promoting NF- $\mathrm{B}$ activation, which in turn inhibited the downstream aryl-hydrocarbon receptor signaling (Zhang et al., 2017).

In the nucleus, a novel insulin-like growth factor 2 mRNAbinding protein 1 (IGF2BP1)-binding lncRNA (LIN28B-AS1) has been associated with pro-inflammatory activity. TLR4 ligation activates canonical NF- $\mathrm{B}$ pathways, followed by release and activation of p65-p52 heterodimers. The p65-p52 heterodimers then shuttle to the nucleus and enhance proinflammatory responses, including facilitating gene transcriptions of IL- 6 , IL- $1 \beta$, and TNF- $\alpha$ by interacting with IGF2BP1 (Perkins, 2007; Rahman and McFadden, 2011; Xie J. et al., 2019). It is noteworthy that LIN28B-AS1-IGF2BP1 binding is essential for IGF2BP1-p65-p52 complex formation, because nuclear LIN28B-AS1 could interact with IGF2BP1 and assemble the IGF2BP1-p65-p52 complex in THP-1 cells (Xie Z. et al., 2019).

Unlike LIN28B-AS1, anti-inflammatory lncRNA-Mirt2 regulates inflammation by blocking the $\mathrm{NF}_{-} \mathrm{B}$ signaling in the cytosol. Mirt2 expression was potently up-regulated in response to LPS. LPS-triggered signaling pathways required the adaptor protein myeloid differentiation marker 88 (MyD88) and tollinterleukin-1 receptor domain-containing adaptor-inducing IFN $\beta$ (TRIF) (Kawai and Akira, 2010). The TLR4-MyD88 binding at the membrane contributed to recruiting and phosphorylating IL-1 receptor associated kinase 1 (IRAK1) and IRAK4 that promote oligomerization and ubiquitination of TNF receptor-associated factor 6 (TRAF6) (Hirotani et al.,
2005; Skaug et al., 2009). However, Mirt2 can bind to TRAF6 in the cytosol and attenuate oligomerization and its Lys63 (K63)linked ubiquitination, which restricts MyD88-dependent NF-kB and MAPK activation and TRAF6-mediated M1 polarization of macrophages. In addition to repressing macrophage inflammation, exotic Mirt2 expression remarkably facilitates IL-4-stimulated expression of multiple M2 markers, including Arg1, CD206, and Ym1, suggesting Mirt2 participates in M2 polarization. But the underlying mechanism remains unclear, and more studies are needed to gain a deeper understanding of the mechanism by which Mirt2 facilitates M2 polarization (Du et al., 2017).

Several findings have confirmed MALAT1 as a key controller of inflammation. Following LPS treatment, NF- $\mathrm{kB}$-dependent enhancement of MALAT1 expression initiates a negative feedback loop. In human THP-1 cells, nuclear NF- $\mathrm{kB}$ triggered the transcription of MALAT1, and after that, MALAT1 interacted with the p50/p65 complex sequestering NF-kB and repressing its DNA-binding activity, which subsequently led to transcription of inflammatory cytokines TNF- $\alpha$, IL- 6 , and IL-1 $\beta$. MALAT1 knockdown enhanced the binding ability of p65 to TNF- $\alpha$ and IL-6 promoters (Zhao et al., 2016).

\section{OX-LDL-STIMULATED LONG NONCODING RNAS}

In addition to responding to TLR4 ligation, MALAT1 facilitates ox-LDL-induced inflammation by controlling CD36 expression. CD36 on the membrane of macrophages is a key scavenger receptor participating in lipid uptake and forming foam cells, and it has a strong affinity for ox-LDL (Tarhda et al., 2013; Chistiakov et al., 2017). Ox-LDL stimulation initiates MALAT1 transcription via NF- $\mathrm{kB} . \beta$-catenin is a transcription factor for $\mathrm{CD} 36$ expression, and $\beta$-catenin gets recruited to the binding site on the CD36 promotor by the enhanced expression of MALAT1 that facilitates lipid uptake in macrophages (Huangfu et al., 2018).

SNHG16, an ox-LDL-sensitive long noncoding small nucleolar RNA, was found to be highly expressed in patients with AS. In an in vitro study, exogenous SNHG16 expression augmented production of pro-inflammatory cytokines by activating NF- $\mathrm{kB}$ signaling cascades. Conversely, SNHG16 knockdown resulted in inhibited IKK $\beta$ expression, $I_{\kappa} B a$ phosphorylation, and p65 phosphorylation. Functionally, SNHG16 gets released into the cytoplasm in response to oxLDL; then, SNHG16 acting as a sponge binds directly to and absorbs miR-17-5p to abolish the inhibitory effect of miR-17 $=5 p$ on $\mathrm{NF}-\kappa \mathrm{B}$ activation. A SNHG16/miR-17-5p/NF- $\mathrm{kB}$ signaling axis promoting an inflammatory response in AS may exist (An al., 2019).

LINC01140 mediates ox-LDL-induced inflammation and plays a protective role on inflammation (He et al., 2020). After ox-LDL stimulation, LINC01140 becomes down-regulated in macrophage-differentiated THP1 cells, whereas p53 mRNA and miR-23b are up-regulated. The expression of inflammation factors, such as MCP-1, TNF- $\alpha$, and IL- $1 \beta$, is repressed potently when p53 is down-regulated. The 


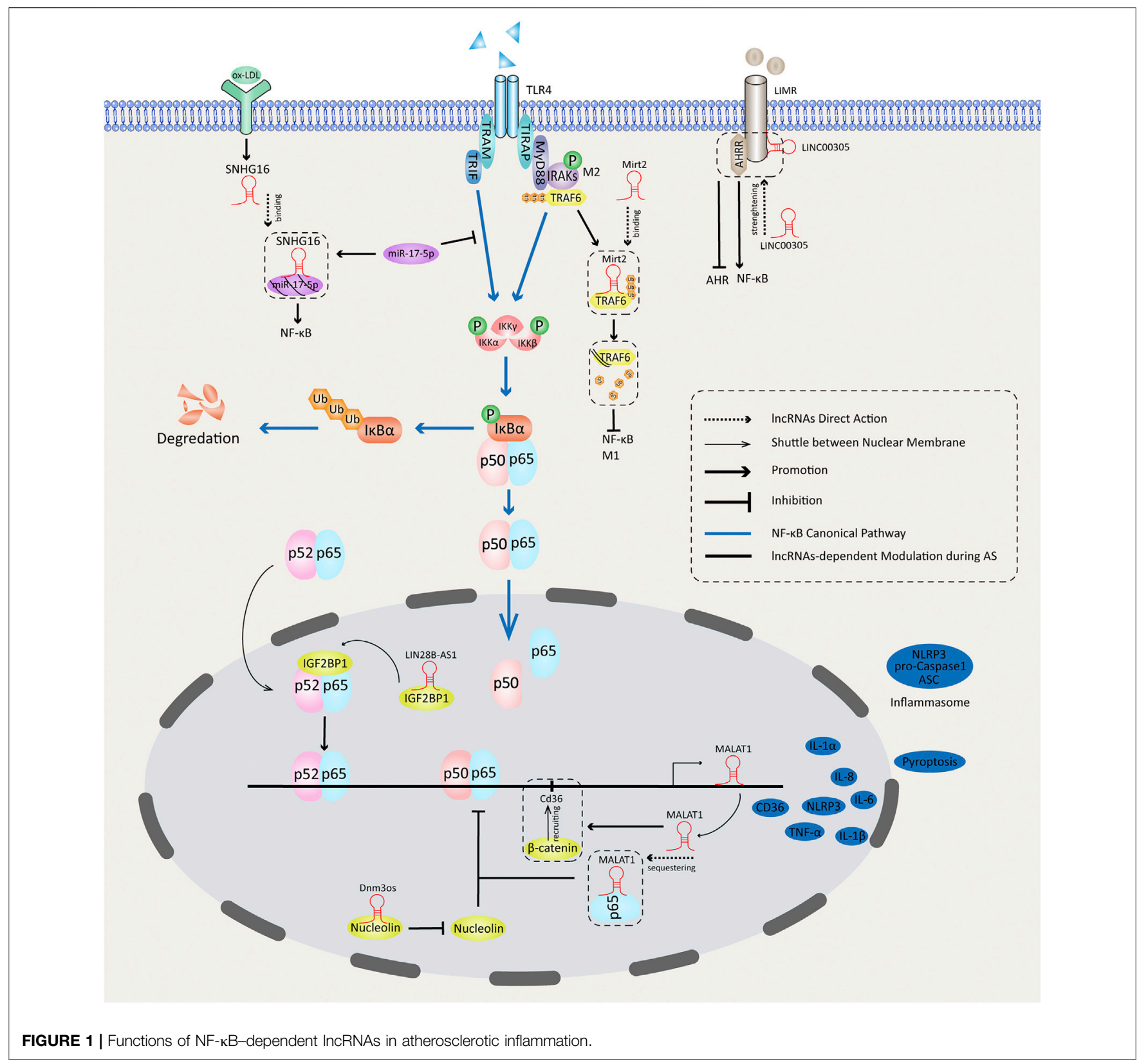

association between p53 and the LINC01140 promoters was shown using a luciferase reporter assay. After transfecting cells with a p53-overexpression vector (pcDNA-p53), LINC01140 expression was repressed and miR-23b expression was enhanced (He et al., 2020).

\section{HIGH GLUCOSE AND PALMITIC ACID-STIMULATED LONG NONCODING RNAS}

High glucose (HG) and palmitic acid (PA) can activate the lncRNA dynamin 3 opposite strand (Dnm3os) promotor and enhance pro-inflammatory actions by targeting nucleolin.
Gene overexpression and knockdown experiments identified Dnm3os as a pro-inflammatory molecule under diabetic conditions. For instance, PA significantly induces the expression of IL-6, TNF, Nos2, and Cd36 in RAW264.7 cells transfected with a Dnm3os expression vector. RNA pull-down assays identified a close interaction between Dnm3os and nucleolin. Nucleolin is a nuclear RNA-binding protein in macrophages (Cong et al., 2011) that can regulate chromatin structure and exert an atheroprotective function. HG and PA substantially decrease the nucleolin protein level. Silencing nucleolin increased the gene expression of inflammatory factors induced by Dnm3os, including that of IL-6 and histone H3K9-acetylation at their promoters (Das et al., 2018). 
In addition to activating lncRNAs through NF-кB, lincRNAEPS, for example, is a nuclear repressor for inflammation that controls the expression of immune response genes (IRGs). Under an endotoxin challenge, lincRNA-EPS-deficient mice displayed exacerbated inflammatory responses and lethality. Gain-offunction and rescue approaches showed that lincRNA-EPS overexpression effectively limited IRG expression. lincRNAEPS localizing at regulatory sites of IRGs interacts with hnRNPL via a CANACA motif to control nucleosome positioning and repress IRG transcriptions (Atianand et al., 2016).

On the other hand, lncRNA uc.48+ modulates P2X7Rmediated diabetic immune and inflammatory responses in RAW264.7 macrophages. P2X7R is protein of the P2X7 receptor and ERK pathway (Ponnusamy et al., 2011; Zanin et al., 2015). HG and free fatty acid (FFA) RAW264.7 cell treatments promoted the expression of uc.48+. Increased expression of uc.48+ in response to HG and FFAs augmented the inflammatory cytokine secretion, ROS formation, and ERK signaling via P2X7R activation (Wu et al., 2018).

Figure 1 summarizes the $\mathrm{NF}_{-\kappa} \mathrm{B}$-associated activities of lncRNAs during AS in macrophages. IncRNAs regulate the expression of NF- $\mathrm{B}$ in both cytosols and nuclei. They can promote or inhibit translocation of $\mathrm{NF}-\kappa \mathrm{B}$ dimers to the nucleus by controlling the phosphorylation of the IKK complex and $I_{\kappa} \mathrm{B} \alpha$. NF- $\mathrm{B}_{\mathrm{B}}$-dependent gene transcriptions are functionally affected by lncRNAs in the nucleus, partially through assembly of functional nuclear proteins complexes. MALAT1 can be expressed through an NF- $\mathrm{\kappa B}$ pathway, and it affects the transcriptions of NF- $\kappa \mathrm{B}-$ dependent inflammatory genes.

\section{LONG NONCODING RNAS IN MACROPHAGE CHOLESTEROL METABOLISM}

Lipid uptake and foam cell formation depend on activation of scavenger receptors, including the type A scavenger receptor (SRA) and the type B CD36 in the macrophages (Kunjathoor et al., 2002). Following lipid uptake, lipid droplets bud off the endoplasmic reticulum (ER) into the cytoplasm. The accumulation of free cholesterol (FC) requires reesterification by the enzyme acyl-cholesterol transferase 1 (ACAT-1) in cells. Excessive FC can be stored in the form of cholesterol esters (CE) (McLaren et al., 2011; Maguire et al., 2019). Furthermore, the efflux of cholesterol can potentially keep cells from foaming. Cholesterol efflux depends mainly on several membrane transporters, such as the ATP-binding cassette transporter 1 (ABCA1) and the ATP-binding cassette subfamily G member-1 (ABCG1); and SR-B1, PPAR, and liver $\mathrm{X}$ receptor a (LXLRa) are key transcriptional factors for this process (Maguire et al., 2019). Notably, ABCA1, ABCG1, and SR-B1 control the removal of cholesterol and phospholipids out of macrophages by directing lipid droplets to apolipoprotein A1 and high-density lipoprotein (HDL) (Moore and Tabas, 2011; Maguire et al., 2019). Dysregulation of cholesterol homeostasis in macrophages results in lipid uptake disturbances, foam cell formation, and the progression of AS. LncRNAs in macrophages have been demonstrated to manage cholesterol loading and foam cell formation. Figure 2 shows a summary of these findings.

Generally, lncRNAs serve as miRNA sponges. Several studies have identified the intricate interplay between lncRNAs and microRNAs in macrophages that significantly affect the cell cholesterol metabolism and lead to foam cell formation and AS development. For example, nuclear-enriched abundant transcript 1 (NEAT1) (Chen et al., 2018; Wang L. et al., 2019) and growth arrest-specific transcript 5 (GAS5) (Ye et al., 2018) are involved in oxidative stress, lipid uptake, and inflammation by targeting miRNAs and may cause exacerbation of atherogenesis. However, RP5-833A20.1 (Hu et al., 2015), the cholesterol homeostasis regulator of miRNA expression (CHROME) (Hennessy et al., 2019), and the H19-imprinted maternally expressed transcript (H19) (Han et al., 2018) can reverse cholesterol metabolism disturbances and alleviate the inflammatory response.

GAS5 is capable of mediating macrophage polarization (Chi et al., 2019; Sun et al., 2017), apoptosis (Chen et al., 2017), and inflammation (Ye et al., 2018). GAS5 is found abundantly in atherosclerotic plaques after ox-LDL treatment. In THP-1 cells, enrichment of GAS5 suppressed the miR-211 expression, aggravating the inflammatory response and stimulating the expression of MMP, whose production in foam cells exacerbates proteolytic rupture of extracellular matrix components in plaque lesions. These findings support the role of GAS5 as a contributor of plaque destabilization in AS (Ye et al., 2018).

The nuclear lncRNA NEAT1 is a pro-atherosclerotic agent shown to serve as a sponge for downstream miR-128 (Chen et al., 2018) and miR-342-3p (Wang et al., 2019) targets. NEAT1 triggered an inflammatory response and oxidative stress by suppressing miR-128 in RAW264.7 cells after ox-LDL stimulation. Down-regulating NEAT1 repressed not only cell proliferation, inflammation, and the oxidative stress process but also inhibited CD36 expression, foam cell formation, and apoptosis (Chen et al., 2018). In addition, the NEAT1-miR-3423 p pathway modulates inflammation and lipid uptake. In THP-1 cells, lipid uptake was inhibited by NEAT1 silencing plus miR-34$3 p$ mimics treatment. Because of this, NEAT1 blockade could suppress the ox-LDL-induced apoptosis and inflammation via miR-342-3p curbing (Wang et al., 2019).

Another nuclear lncRNA RP5-833A20.1 is antiatherosclerotic. The expression of RP5-833A20.1 under oxLDL or ac-LDL treatment weakens the expression of nuclear factor IA (NFIA) in THP-1-derived foam cells. In an $\mathrm{ApoE}^{-/-}$ mice model, NFIA overexpression enhanced HDL cholesterol (HDL-C), decreased the production of LDL cholesterol (LDL-C) and very LDL cholesterol (VLDL-C), and reduced the secretion of inflammatory cytokines in plasma. Meanwhile, NFIA promoted reverse cholesterol transport across cell membranes by stimulating ABCA1 and ABCG1 expression. ABCA1 and ABCG1 can deliver cholesterol across cell membranes (Stefulj et al., 2009) and may enable AS regression. Overexpressing RP5- 


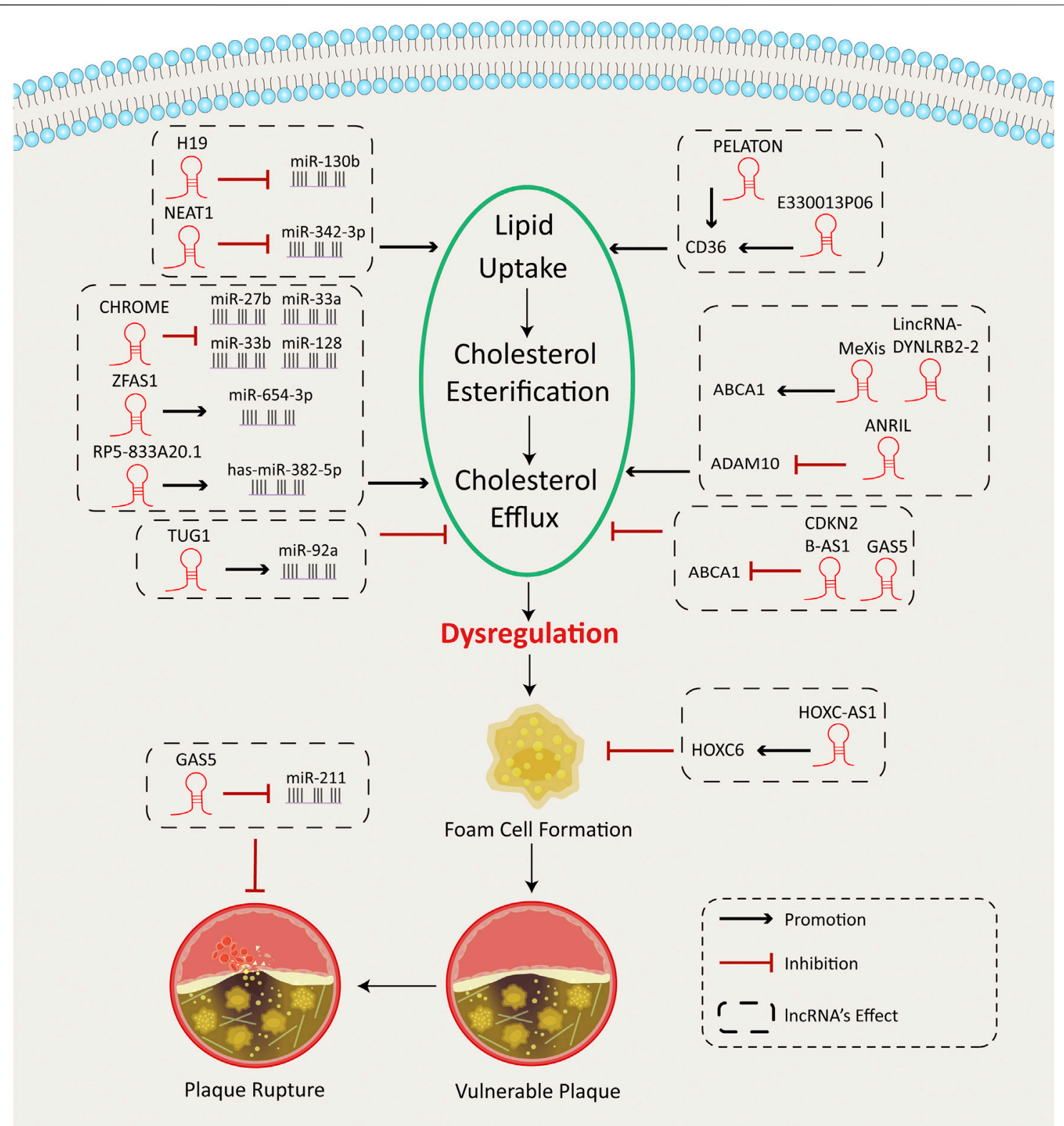

FIGURE 2 | Cholesterol metabolism functions of IncRNAs in macrophages.

833A20.1 and hsa-miR-382-5p mimics in vitro effectively downregulated the expression of $A B C A 1$ and ABCG1 but elevated the expression of SRA1, CD36, and NF- $\mathrm{kB}$. As a result of this, lncRNA RP5-833A20.1 can stimulate cholesterol efflux in human macrophages and relieve the inflammatory response via the RP5-833A20.1- has-miR-382-5p pathway ( $\mathrm{Hu}$ et al., 2015).

Furthermore, CHROME levels in the plasma and atherosclerotic plaques of patients with coronary artery disease (CAD) are elevated. Cells expressing wild-type CHROME in vitro inhibit the expression of miRNAs, such as miR-27b, miR-33a, miR-33b, and miR-128; these miRNAs suppress cholesterol efflux and prohibit HDL biogenesis.
CHROME derepresses these collective target genes through its miRNA interactions, which further affects cholesterol transport. Cells lacking CHROME express lower levels of ABCA1, cannot efflux cholesterol, and present reduced formation of nascent HDL particles in response to activating sterol-activated liver $\mathrm{X}$ receptor (LXR), leading to reduced expression of genes involved in the response to cholesterol excess in human hepatocytes and macrophages (Hennessy et al., 2019).

H19 participates in many pathological processes, including tumorigenesis (Ghafouri-Fard et al., 2020), cerebral ischemiareperfusion injury (Wang et al., 2017), and acute myocardial infarction (Yu and Dong, 2018). H19 is highly expressed, while miR-130b is down-regulated in blood samples of patients with 
TABLE 1 | Summary of atherosclerosis-related IncRNAs expressed in macrophage.

\begin{tabular}{|c|c|c|c|c|c|c|c|}
\hline IncRNA & Full name & Location & Stimulus & Cells & Function & Mechanism & Reference \\
\hline \multicolumn{8}{|c|}{ Macrophage differentiation } \\
\hline Lnc-MC & Long noncoding monocytic RNA & Cytoplasm & Pam3CSK4 & Macrophage HL-60 & $\begin{array}{l}\text { Monocyte/macrophage } \\
\text { differentiation }\end{array}$ & $\begin{array}{l}\text { Sequestering and soaking up miR- } \\
\text { 199a-5p to release the expression } \\
\text { of ACVR1B }\end{array}$ & $\begin{array}{l}\text { Chen et al. } \\
\text { (2015) }\end{array}$ \\
\hline \multicolumn{8}{|c|}{ Macrophage phenotypic switching } \\
\hline TCONS_00019715 & - & - & IFN- $\alpha$ LPS & Macrophage & Macrophage polarization & $\begin{array}{l}\text { Reducing M1 elevating M2 may be } \\
\text { through regulating PAK1 }\end{array}$ & $\begin{array}{l}\text { Huang Z. et al. } \\
\text { (2016) }\end{array}$ \\
\hline Mirt2 & $\begin{array}{l}\text { Myocardial infraction-associated } \\
\text { transcript } 2\end{array}$ & Cytoplasm & LPS & Macrophage & $\begin{array}{l}\text { Macrophage polarization and } \\
\text { anti-inflammation }\end{array}$ & $\begin{array}{l}\text { Blocking the MyD88-mediated } \\
\text { MAPK and NF-kB activities to inhibit } \\
\text { M1 polarization }\end{array}$ & Du et al. (2017) \\
\hline \multicolumn{8}{|l|}{ Macrophage apoptosis } \\
\hline CERNA1 & - & $\begin{array}{l}\text { Cytoplasm and } \\
\text { nucleus }\end{array}$ & Ox-LDL & $\begin{array}{l}\text { Vascular smooth muscle } \\
\text { cells and macrophage }\end{array}$ & $\begin{array}{l}\text { Atherosclerotic plaque } \\
\text { stabilization }\end{array}$ & $\begin{array}{l}\text { Increasing API5 to inhibit apoptosis } \\
\text { of VSMCs and anti-inflammatory } \\
\text { macrophages }\end{array}$ & Lu et al. (2019) \\
\hline RAPIA & $\begin{array}{l}\text { LncRNA associated with the } \\
\text { progression and intervention of } \\
\text { atherosclerosis }\end{array}$ & Cytoplasm & - & Macrophage & $\begin{array}{l}\text { Macrophage proliferation and } \\
\text { apoptosis }\end{array}$ & $\begin{array}{l}\text { Binding to miRNA-183-5p to } \\
\text { promote proliferation and promote } \\
\text { apoptosis of macrophages }\end{array}$ & Sun et al. (2020) \\
\hline \multicolumn{8}{|l|}{ Macrophage pyroptosis } \\
\hline MALAT1 & $\begin{array}{l}\text { Metastasis-associated lung } \\
\text { adenocarcinoma transcript } 1\end{array}$ & Nucleus & $\begin{array}{l}\text { Low-dose } \\
\text { sinapic acid }\end{array}$ & Macrophage & Macrophage pyroptosis & $\begin{array}{l}\text { Chronic low-dose SA treatment } \\
\text { could block the function of } \\
\text { MALAT1-dependent NLRP3 } \\
\text { inflammasome, consequently inhibit } \\
\text { pyroptosis, and systemic } \\
\text { inflammatory response }\end{array}$ & $\begin{array}{l}\text { Yong et al. } \\
\text { (2018) }\end{array}$ \\
\hline \multicolumn{8}{|c|}{ Atherosclerotic inflammation } \\
\hline Mirt2 & $\begin{array}{l}\text { Myocardial infraction-associated } \\
\text { transcript } 2\end{array}$ & Cytoplasm & LPS & Macrophage & $\begin{array}{l}\text { Macrophage polarization and } \\
\text { anti-inflammation }\end{array}$ & $\begin{array}{l}\text { Blocking the MyD88-mediated } \\
\text { MAPK and NF-KB activities to inhibit } \\
\text { M1 polarization }\end{array}$ & Du et al. (2017) \\
\hline LINC00305 & - & Cytoplasm & LPS & Macrophage & Pro-inflammation & $\begin{array}{l}\text { Binding to LIMR then promoted } \\
\text { nuclear localization of AHRR to } \\
\text { activate NF-KB }\end{array}$ & $\begin{array}{l}\text { Zhang et al. } \\
\text { (2017) }\end{array}$ \\
\hline LIN28B-AS1 & - & Nucleus & LPS & Macrophage and monocyte & Pro-inflammation & $\begin{array}{l}\text { Increasing IGF2BP1-p65-p52 } \\
\text { association to activate NF-kB } \\
\text { signaling }\end{array}$ & $\begin{array}{l}\text { Xie Z. et al. } \\
(2019)\end{array}$ \\
\hline MALAT1 & $\begin{array}{l}\text { Metastasis-associated lung } \\
\text { adenocarcinoma transcript } 1\end{array}$ & Nucleus & LPS & Macrophage & $\begin{array}{l}\text { Decreased transcription of } \\
\text { inflammatory cytokines }\end{array}$ & $\begin{array}{l}\text { Interacting with NF-kB p50/p65 } \\
\text { dimmers to sequester NF-kB and } \\
\text { decrease cytokine transcription }\end{array}$ & $\begin{array}{l}\text { Zhao et al. } \\
\text { (2016) }\end{array}$ \\
\hline SNHG16 & Small nucleolar RNA host gene 16 & Cytoplasm & Ox-LDL & Macrophage & $\begin{array}{l}\text { Cell proliferation and pro- } \\
\text { inflammation }\end{array}$ & $\begin{array}{l}\text { Binding to and absorbed miR-17-5p } \\
\text { to release the activity of NF-kB } \\
\text { pathway }\end{array}$ & An et al. (2019) \\
\hline LINC01140 & - & - & Ox-LDL & Macrophage & Anti-inflammation & $\begin{array}{l}\text { Binding to miR-23b in order to } \\
\text { down-regulate p53 and decrease } \\
\text { the expression of inflammation } \\
\text { factors }\end{array}$ & He et al. (2020) \\
\hline Dnm3os & Dynamin 3 opposite strand & Nucleus & $P A$ and $H G$ & Macrophage & Pro-inflammation & $\begin{array}{l}\text { Decreasing nucleolin protein levels } \\
\text { to increase inflammatory gene } \\
\text { expression }\end{array}$ & Das et al. (2018) \\
\hline
\end{tabular}


TABLE 1 | (Continued) Summary of atherosclerosis-related IncRNAs expressed in macrophage.

\section{IncRNA}

lincRNA-EPS

Full name

LincRNA erythroid prosurviva

Location

Nucleus

Stimulus

Pam3CSK4

Cells

Macrophage

$H G$ and FFAs

Macrophage

Nucleus

Ox-LDL

Nuclear-enriched abundant transcript 1

Macrophage

GAS5

Growth arrest-specific transcript 5 Cytoplasm

Nucleus

Ox-LDL

Macrophage

Nucleus

RP5-833A20.1

Zinc finger NFX1-type containing 1 Cytoplasm antisense RNA 1

Cholesterol homeostasis regulator of Cytoplasm miRNA expression

$\mathrm{H} 19$

PELATON/LINC01272 transcript

hed IncRNA in

mactic and inflammatory

TUG1

bowel macrophage regulation

Nucleus

Taurine up-regulated gene 1

E330013P06

$-$

$-\quad$ Ox-LDL

NC01228
HG PA

Macrophage

Ox-LDL and Ac- Macrophage-derived foam Anti-atherosclerotic LDL cells

Macrophage-derived foam Anti-atherosclerotic cells

XR agonist Hepatocytes and Anti-atherosclerotic

Ox-LDL Macrophage

Macrophage

Macrophage

Pro-atherogenic

Macrophage

\section{Mechanism}

Reference

Controlling nucleosome positioning Atianand et al.

and repressing transcription

(2016)

expression of inflammatory

cytokines by targeting hnRNPL

Evoking P2X7R-mediated cytokine Wu et al. (2018)

production, ROS activity, and

reaction of the ERK pathway

Inflammation and oxidative

Sponging and inhibiting miR-128 to Chen et at.

trigger inflammation and oxidative (2018)

stress and to increase CD36

Inflammation and lipid uptake Inducing ox-LDL-induced apoptosis Wang L. et al.

and inflammation via targeting miR- (2019)

$342-3 p$

Suppressing the miR-211

Ye et al. $(2018)$

expression to aggravate

inflammatory response and the

expression of MMP exacerbating

plaque rupture

Promoting atherosclerosis

Meng et al.

development through targeting

transcription

Reducing cholesterol efflux and

alleviating inflammatory responses

via RP5-833A20.1-has-miR-382-

$5 p$ pathway

Ameliorating inflammation and

reducing cholesterol efflux by

Tang et al

targeting miR-654-3p-ADAM10

RAB22A axis

Interacting with microRNAs to curb Hennessy et al.

their repression on cholesterol efflux (2019)

and $\mathrm{HDL}$ biogenesis

Regulating adipogenesis and

inflammation by inhibiting miR-130

Inducing CD36 expression to

promote phagocytosis, ROS

production, and Ox-LDL uptake

Dysregulating high-density

lipoprotein metabolism and

Hu et al. (2015)

ux through inhibiting

miR-92a and improving FXR1

ncreasing inflammatory genes

along with foam cell formation

through up-regulating CD36

expression

Up-regulating GPR 119 and ABCA1 Hu et al. (2014)

by the GLP1-R signaling pathway

(Continued on following page) 


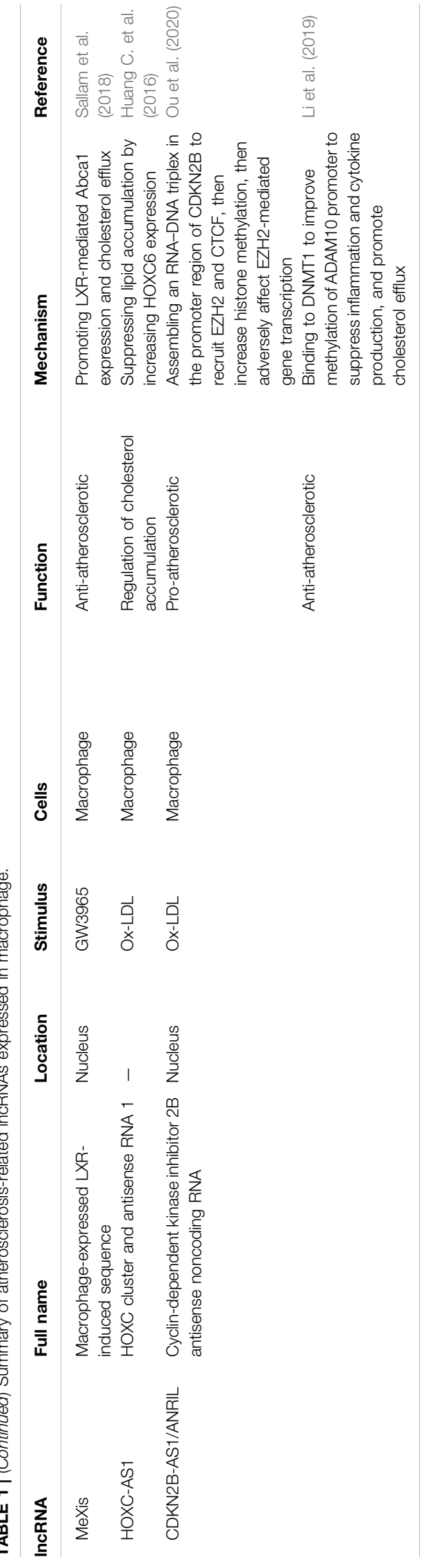

AS. This suggests that in ox-LDL stimulated RAW264.7 cells, H19 participates in adipogenesis and the inflammatory response by inhibiting the activity of miR-130b. miR-130b is a target for H19; H19-induced miR-130b expression after ox-LDL treatment stimulates anti-inflammatory cytokine production and decreases pro-inflammatory cytokine levels. Knocking down H19 using shRNAs alleviated lipid metabolism disturbances and decreased the inflammatory response by mitigating lipid accumulation and promoting the lipid metabolism (Han et al., 2018). H19 is also a regulator of hepatic inflammation during cholestasis that secretes exosome cargos in cholangiocytes (Li et al., 2020).

The plaque-enriched IncRNA in atherosclerotic and inflammatory bowel macrophage regulation (PELATON) lncRNA is a potential regulator of macrophage phagocytosis. After being confirmed by in situ hybridization, PELATON was enriched in unstable human atherosclerotic plaques with a necrotic core and plaque shoulders and colocalized with the M1 marker CD68. Knocking down PELATON in monocyte-derived macrophages markedly reduced the cell phagocytotic performance by reducing the CD36 mRNA (Hung et al., 2019). lncRNA E330013P06 (E33) also caused foam cell formation by upregulating CD36 expression. Under type 2 diabetic (T2D) conditions, HG and PA treatment of macrophages greatly upregulates the expression of E33. Exogenous expression of E33 highly induces inflammation by increasing inflammatory expression of Nos2, Il6, and Ptgs2 genes, along with foam cell formation through up-regulation of CD36 expression, resulting in pro-atherogenic macrophages responses (Reddy et al., 2014).

The pro-atherosclerotic taurine up-regulated gene 1 (TUG1) can worsen AS via the miR-92a/FXR1 axis (Yang and Li, 2020). TUG1 overexpression increases plaque size and enhances macrophage recruitment to the plaque area by targeting apolipoprotein (apo) $\mathrm{M}$ in $\mathrm{ApoE}^{-/-}$mice. Generally, ApoM is a critical lipocalin for delivering lipid sphingosine-1-phosphate (S1P). ApoM delivers S1P to its S1P receptors on endothelial cells. The anti-atherosclerotic ApoM can regulate high-density lipoprotein metabolism, protecting against oxidation and mediating CE (Christoffersen et al., 2011; Nádró et al., 2018). TUG1 was found to down-regulate ApoM levels via miR-92a inhibition and FXR1 stimulation in mouse liver NCTC 1469 cells. In RAW264.7 cells, TUG1 overexpression significantly decreased ABCA1 and ABCG1 expressions, which consequently slowed down the CE rate (Yang and $\mathrm{Li}, 2020$ ).

In recent studies, GAS5 (Meng et al., 2020) and cyclindependent kinase inhibitor $2 \mathrm{~B}$ antisense noncoding RNA (CDKN2B-AS1, also known as ANRIL) (Ou et al., 2020) showed an important role on AS development through its EZH2-mediated ABCA1 transcription targeting. In Meng's work, GAS5 stimulated lipid accumulation and prevented cholesterol efflux by regulating ABCA1 in macrophagederived foam cells (Meng et al., 2020).

By recruiting zeste homolog $2(\mathrm{EZH} 2)$, one of the enzymatic factors of the polycomb repressive complex (Lu et al., 2018), to the promotor region of ABCA1, GAS5 transcriptionally represses its target genes (Shi et al., 2018). Knocking down GAS5 can greatly reverse cholesterol transportation and decrease lipid accumulation 
by alleviating the EZH2-dependent transcriptional inhibition of $\mathrm{ABCA} 1$. EZH2 enhances the triple methylation of lysine 27 $(\mathrm{H} 3 \mathrm{~K} 27)$ in the promoter region of ABCA1. GAS5 transcriptionally inhibits ABCA1 by binding to the EZH2 enhancer. EZH2 can promote AS progression by efficiently blocking ABCA1 transcription in AS (Lv et al., 2016).

Similarly, the lncRNA CDKN2B-AS1 promotes cholesterol uptake and accumulation and inhibits macrophage reverse cholesterol transport (mRCT) in macrophage-derived foam cells (Ou et al., 2020). The detrimental effects of CDKN2B knockdown on atherosclerotic lesions could be reversed by sh-CDKN2B-AS1 in an in vivo mouse model. Mechanically, CDKN2B-AS1 can package an RNA-DNA triplex in the CDKN2B promoter region. This triplex can recruit $\mathrm{EZH} 2$ and $\mathrm{CTCF}$ to the promoter region of $\mathrm{CDKN} 2 \mathrm{~B}$ to increase histone methylation, which then adversely affects CDKN2B transcription (Ou et al., 2020).

In contrast, LincRNA-DYNLRB2-2, macrophage-expressed LXR-induced sequence (MeXis), HOXC cluster antisense RNA 1 (HOXC-AS1), and ANRIL are anti-atherogenic molecules that modulate cholesterol efflux and cholesterol accumulation. Among them, LincRNA-DYNLRB2-2 (Hu et al., 2014) and MeXis (Hennessy et al., 2019) both target ABCA1 to regulate the cholesterol metabolism. The ox-LDL-induced increased lincRNADYNLRB2-2 expression in THP-1 macrophage-derived foam cells ameliorates inflammation by up-regulating $G$ protein-coupled receptor 119 (GPR119), meanwhile improving ABCA1-regulated cholesterol efflux via a glucagon-like peptide 1 receptor (GLP-1R) signaling pathway. GPR119 is an anti-inflammatory regulator that induces ABCA1 expression and can be controlled by GLP$1 \mathrm{R}$-mediated signaling cascades. By inducing the expression of ABCA1, GPR119 promotes cellular cholesterol efflux through apoA-I. Therefore, lincRNA-DYNLRB2-2 prevents atherosclerotic plaque formation by repressing expression of inflammation and adhesion molecules and increasing cholesterol efflux ( $\mathrm{Hu}$ et al., 2014). MeXis is an amplifier of the critical cholesterol efflux gene Abcal, whose transcription is mediated by LXR. In response to LXR signaling, MeXis expression induction in macrophages promotes the expression of Abcal and consequently improves cholesterol efflux. MeXis knockout in the bone marrow of mice represses Abcal and inflammatory gene expression, causing an impaired cell response to cholesterol overload and plaque development. The LXR-MeXisAbcal axis may reverse cholesterol delivery and play a protective role on AS development (Sallam et al., 2018; Xie Y. et al., 2019). Additionally, ANRIL could serve as a biomarker candidate of AS that is up-regulated in atherosclerotic plaques and in patients' plasma (Hao et al., 2016). ANRIL also reduces inflammation and promotes cholesterol efflux by blocking ADAM10 expression. ADAM10 can shed or cleave several molecules on cell surface-like adhesion molecules and cytokines (van der Vorst et al., 2018). As a result of this, ANRIL suppresses the cytokine production and inflammation induced by AS, and it promotes cholesterol efflux (Li et al., 2019).

Moreover, the oncogenic LncRNA zinc finger NFX1-type containing one antisense RNA 1 (ZFAS1) is a viable target to ameliorate the development of AS because it reduces the cholesterol efflux rate and facilitates inflammation (Tang et al., 2020). In THP-1 macrophage-induced macrophages, overexpressing ZFAS1 promotes inflammatory responses and blocks cholesterol efflux. ZFAS1 is an upstream factor for miR-654-3p, which can target and suppress the expression of ADAM10 and RAB22A. In short, ZFAS1 can positively mediate the expression of ADAM10 and RAB22A by sponging miR-654-3p (Tang et al., 2020).

Lipid uptake, cholesterol esterification, and efflux are the main processes for the macrophage lipid metabolism. Disturbance of these processes leads to lipid accumulation and finally causes foam cell formation. IncRNAs participate in macrophage lipid metabolism and atherosclerotic plaque formation by targeting microRNAs or controlling the gene expression of important lipid metabolic enzymes or proteins.

HOXC cluster antisense RNA 1 (HOXC-AS1) exerts an inhibitory effect on ox-LDL-mediated cholesterol accumulation by improving homeobox C6 (HOXC6) expression in human THP1 cells. HOX genes have significant regulatory effects on the cardiovascular system through vasculature function regulation (Miano et al., 1996). HOXC-AS1 and HOXC6 are both downregulated in human atherosclerotic plaques. Lentivirus-mediated overexpression of HOXC-AS1 promoted the expression of HOXC6 and blocked ox-LDL-induced foam cell formation and disruption of cholesterol homeostasis in THP-1 cells. Ox-LDL could repress HOXC6 expression by reducing HOXC-AS1, partly suppressing Ox-LDL-mediated cholesterol accumulation to prevent AS (Huang C. et al., 2016).

Dysregulated lipid metabolism in macrophages is a potential cause of the foam cell formation, which speeds up the progress of AS. Several lncRNAs mentioned above play important roles during this process.

\section{LONG NONCODING RNAS AS POTENTIAL BIOMARKERS AND THERAPEUTIC PERSPECTIVES}

Among the noncoding RNAs, many miRNAs have been identified as disease biomarkers for a variety of cardiovascular diseases (CVDs) (Indolfi et al., 2019). Advances in the field of lncRNAs have provided evidence that these molecules display specific characteristics that make them attractive as prospective therapeutic targets to be exploited for clinical use (Indolfi et al., 2019). The expression profiles of lncRNAs have revealed individual $\operatorname{lncRNAs}$ or clusters of $\operatorname{lncRNAs}$ within plaque lesions. These molecules are potential biomarker candidates and can be seen as prospective therapeutic targets during AS progression (Fasolo et al., 2019; Indolfi et al., 2019).

On the one hand, as potential biomarkers, some "sponge" lncRNAs are more robust than miRNAs. LncRNAs can be upstream targets of miRNAs. For example, the macrophage anti-atherosclerotic lncRNA ZFAS1 serves as sponge that binds to miR-654-3p and improves the expression of ADAM10 and RAB22A (Tang et al., 2020). Moreover, some lncRNAs "sponges" are capable of interacting with more than one miRNA. CHROME can exert regulatory roles on cholesterol efflux and reverses cholesterol transport by reducing the expression of four miRNAs, namely, miR-27b, miR-33a, miR33b, and miR-128 (Hennessy et al., 2019). Several miRNAs are 
regulated by a single lncRNA; therefore, targeting such lncRNAs can be convenient (Indolfi et al., 2019).

On the other hand, IncRNAs can be biomarkers to predict different AS stages. RAPIA, for instance, is highly expressed in advanced atherosclerotic sites in mice models. The high level of RAPIA expression in atherosclerotic plaques may predict the occurrence of advanced AS (Sun et al., 2020). Suppression of RAPIA showed similar effects to those of atorvastatin on advanced atherosclerotic plaques by attenuating lipid accumulation and decreasing plaque size in advanced atherosclerotic plaques of mice models. RAPIA has been seen as a promising therapeutic target for treating advanced atherosclerotic lesions, especially in patients resistant or intolerant to statins.

LncRNAs offer the promise of a noninvasive diagnostic tool to manage AS. These molecules can be detected in the patients' sera and are considered attractive disease biomarker candidates (Zeng et al., 2018). ANRIL is a potential AS biomarker as it was found to increase in human atherosclerotic plaques and plasma (Hao et al., 2016). In a clinical study, GAS5 was specifically down-regulated in the sera of patients with CAD (Yin et al., 2017): GAS5 expression was greatly down-regulated in patients with CAD compared to its levels in normal controls and in patients with diabetes mellitus (the expression levels of GAS5 were decreased only in patients with CAD) (Indolfi et al., 2019). The expression of CHROME was also found to be high in the sera of patients with CAD and atherosclerotic plaques (Hennessy et al., 2019). Thus, significant high levels of these candidate lncRNAs in the blood may be predictors of CAD.

\section{FUTURE PERSPECTIVES AND CONCLUSION}

As Koelwyn stated, identifying the changing patterns of metabolism in monocytes and macrophages during early atherogenesis and figuring out at which point these processes become maladaptive and progress to the next stage are important. The progression of advanced AS can trigger acute cardiovascular diseases, like heart attack and

\section{REFERENCES}

An, J. H., Chen, Z. Y., Ma, Q. L., Wang, H. J., Zhang, J. Q., and Shi, F. W. (2019). LncRNA SNHG16 promoted proliferation and inflammatory response of macrophages through miR-17-5p/NF- $\kappa B$ signaling pathway in patients with atherosclerosis. Eur. Rev. Med. Pharmacol. Sci. 23, 8665-8677. doi:10.26355/ eurrev_201910_19184

Anderson, C. F., Gerber, J. S., and Mosser, D. M. (2002). Modulating macrophage function with IgG immune complexes. J. Endotoxin Res. 8, 477-481. doi:10. 1179/09680510212500111810.1177/09680519020080060501

Anderson, K. L., Smith, K. A., Conners, K., McKercher, S. R., Maki, R. A., and Torbett, B. E. (1998). Myeloid development is selectively disrupted in PU.1 null mice. Blood 91, 3702-3710. doi:10.1182/blood.v91.10.3702

Atianand, M. K., Hu, W., Satpathy, A. T., Shen, Y., Ricci, E. P., Alvarez-Dominguez, J. R., et al. (2016). A long noncoding RNA lincRNA-EPS acts as a transcriptional brake to restrain inflammation. Cell 165, 1672-1685. doi:10.1016/j.cell.2016.05.075 stroke. Understanding the changing metabolism of macrophages across all stages of AS development is urgent, as is identifying the timing of early foam cell lesion formations, the progression to advanced plaques, and the rupture of vulnerable plaques (Koelwyn et al., 2018). Several lines of evidence have suggested that lncRNAs could be involved in regulating macrophage inflammation, macrophage cholesterol loading, macrophage differentiation, polarization, and apoptosis during the development of AS. Additionally, lncRNAs are promising candidates for AS biomarkers and potential therapeutic targets, like ANRIL, which was found to be greatly increased in patients' plasma (Hao et al., 2016), or the fact that blocking RAPPIA can partially mimic the effect of atorvastatin (Sun et al., 2020). We believe macrophage-related lncRNAs provide a novel and unique perspective to investigate the crossroads between chronic inflammation and AS. Future studies need to provide insights into the lncRNAs' functions in macrophages and explain how they function in the development of AS.

\section{AUTHOR CONTRIBUTIONS}

XM designed the review, gathered the data, drafted the initial manuscript, and revised the manuscript. FC and HL conceptualized and designed the review, coordinated, supervised, and critically reviewed the manuscript for important intellectual content. All authors approved the final manuscript as submitted and agreed to be accountable for all aspects of the work.

\section{FUNDING}

The National Natural Science Foundation of China, No. 81670735 to FC. The National Natural Science Foundation of China, No. 81400802 and Outstanding Youth Training Project from Shanghai Ninth People's Hospital the National Natural Science Foundation of China, jyyq 08201607 to HL.

Baker, R., and Ghosh, S. (2010). Direct activation of protein kinases by ubiquitin. J. Mol. Cell Biol. 2, 20-22. doi:10.1093/jmcb/mjp029

Bergsbaken, T., Fink, S. L., and Cookson, B. T. (2009). Pyroptosis: host cell death and inflammation. Nat. Rev. Microbiol. 7, 99-109. doi:10.1038/nrmicro2070

Brandstätter, O., Schanz, O., Vorac, J., König, J., Mori, T., Maruyama, T., et al. (2016). Balancing intestinal and systemic inflammation through cell typespecific expression of the aryl hydrocarbon receptor repressor. Sci. Rep. 6, 26091. doi:10.1038/srep26091

Carrieri, C., Cimatti, L., Biagioli, M., Beugnet, A., Zucchelli, S., Fedele, S., et al. (2012). Long non-coding antisense RNA controls Uchll translation through an embedded SINEB2 repeat. Nature 491, 454-457. doi:10.1038/nature11508

Chen, D. D., Hui, L. L., Zhang, X. C., and Chang, Q. (2018). NEAT1 contributes to ox-LDL-induced inflammation and oxidative stress in macrophages through inhibiting miR-128. J. Cell. Biochem. 120, 2493. doi:10.1002/jcb.27541

Chen, L., Yang, W., Guo, Y., Chen, W., Zheng, P., Zeng, J., et al. (2017) Exosomal IncRNA GAS5 regulates the apoptosis of macrophages and vascular endothelial cells in atherosclerosis. PLoS One 12 e0185406. doi:10.1371/journal.pone.0185406 
Chen, M.-T., Lin, H.-S., Shen, C., Ma, Y.-N., Wang, F., Zhao, H.-L., et al. (2015). The PU.1-Regulated long noncoding RNA lnc-MC controls human monocyte/ macrophage differentiation through interaction with MicroRNA-199a-5p. Mol. Cell Biol. 35, 3212-3224. doi:10.1128/MCB.00429-15

Chi, X., Ding, B., Zhang, L., Zhang, J., Wang, J., and Zhang, W. (2019). IncRNA GAS5 promotes M1 macrophage polarization via miR-455-5p/SOCS3 pathway in childhood pneumonia. J. Cell. Physiol. 234, 13242-13251. doi:10.1002/jcp.27996

Chinetti-Gbaguidi, G., and Staels, B. (2011). Macrophage polarization in metabolic disorders. Curr. Opin. Lipidol. 22, 365-372. doi:10.1097/MOL.0b013e32834a77b4

Chistiakov, D. A., Melnichenko, A. A., Myasoedova, V. A., Grechko, A. V., and Orekhov, A. N. (2017). Mechanisms of foam cell formation in atherosclerosis. J. Mol. Med. 95, 1153-1165. doi:10.1007/s00109-017-1575-8

Christoffersen, C., Obinata, H., Kumaraswamy, S. B., Galvani, S., Ahnström, J., Sevvana, M., et al. (2011). Endothelium-protective sphingosine-1-phosphate provided by HDL-associated apolipoprotein M. Proc. Natl. Acad. Sci. U.S.A. 108, 9613-9618. doi:10.1073/pnas.1103187108

Cong, R., Das, S., and Bouvet, P. (2011). “The multiple properties and functions of nucleolin" in The nucleolus. Editor M. O. J. Olson (New York, NY: Springer New York), 185-212.

Crowther, M. A. (2005). Pathogenesis of atherosclerosis. Hematol. Am. Soc. Hematol. Educ. Progr. 2005, 436-441. doi:10.1182/asheducation-2005.1.436

Das, S., Reddy, M. A., Senapati, P., Stapleton, K., Lanting, L., Wang, M., et al. (2018). Diabetes mellitus-induced long noncoding RNA Dnm3os regulates macrophage functions and inflammation via nuclear mechanisms. Arterioscler. Thromb. Vascu. Biol. 38, 1806-1820. doi:10.1161/atvbaha.117.310663

Derrien, T., Johnson, R., Bussotti, G., Tanzer, A., Djebali, S., Tilgner, H., et al. (2012). The GENCODE v7 catalog of human long noncoding RNAs: analysis of their gene structure, evolution, and expression. Genome Res. 22, 1775-1789. doi:10.1101/gr.132159.111

Donaldson, C. J., Lao, K. H., and Zeng, L. (2018). The salient role of microRNAs in atherogenesis. J. Mol. Cell. Cardiol. 122, 98-113. doi:10.1016/j.yjmcc.2018.08.004

Du, M., Yuan, L., Tan, X., Huang, D., Wang, X., Zheng, Z., et al. (2017). The LPSinducible lncRNA Mirt2 is a negative regulator of inflammation. Nat. Commun. 8, 2049. doi:10.1038/s41467-017-02229-1

Engreitz, J. M., Haines, J. E., Perez, E. M., Munson, G., Chen, J., Kane, M., et al. (2016). Local regulation of gene expression by lncRNA promoters, transcription and splicing. Nature 539, 452-455. doi:10.1038/nature20149

Fasolo, F., Di Gregoli, K., Maegdefessel, L., and Johnson, J. L. (2019). Non-coding RNAs in cardiovascular cell biology and atherosclerosis. Cardiovasc. Res. 115, 1732-1756. doi: $10.1093 / \mathrm{cvr} / \mathrm{cvz} 203$

Gao, J., Wang, F., Wu, P., Chen, Y., and Jia, Y. (2020). Aberrant LncRNA expression in leukemia. J. Cancer 11, 4284-4296. doi:10.7150/jca.42093

Ghafouri-Fard, S., Esmaeili, M., and Taheri, M. (2020). H19 lncRNA: roles in tumorigenesis. Biomed. Pharmacother. 123, 109774. doi:10.1016/j.biopha.2019. 109774

Han, Y., Ma, J., Wang, J., and Wang, L. (2018). Silencing of H19 inhibits the adipogenesis and inflammation response in ox-LDL-treated Raw264.7 cells by up-regulating miR-130b. Mol. Immunol. 93, 107-114. doi:10.1016/j.molimm. 2017.11.017

Hansen, T. B., Jensen, T. I., Clausen, B. H., Bramsen, J. B., Finsen, B., Damgaard, C. K., et al. (2013). Natural RNA circles function as efficient microRNA sponges. Nature 495, 384-388. doi:10.1038/nature11993

Hao, L., Hongming, Z., and Junbo, G. (2016). Long noncoding RNA: recent updates in atherosclerosis. Int. J. Biol. Sci. 12, 898-910. doi:10.7150/ijbs.14430

Hayden, M. S., and Ghosh, S. (2014). Regulation of NF- $\kappa B$ by TNF family cytokines. Semin. Immunol. 26, 253-266. doi:10.1016/j.smim.2014.05.004

He, L., Zhao, X., and He, L. (2020). LINC01140 alleviates the oxidized low-density lipoprotein-induced inflammatory response in macrophages via suppressing miR-23b. Inflammation 43, 66-73. doi:10.1007/s10753-019-01094-y

Hennessy, E. J., van Solingen, C., Scacalossi, K. R., Ouimet, M., Afonso, M. S., Prins, J., et al. (2019). The long noncoding RNA CHROME regulates cholesterol homeostasis in primates. Nat. Metab. 1, 98-110. doi:10.1038/s42255-018-0004-9

Hirotani, T., Yamamoto, M., Kumagai, Y., Uematsu, S., Kawase, I., Takeuchi, O., et al. (2005). Regulation of lipopolysaccharide-inducible genes by MyD88 and Toll/IL-1 domain containing adaptor inducing IFN- $\beta$. Biochem. Biophys. Res. Commun. 328, 383-392. doi:10.1016/j.bbrc.2004.12.184

Hu, Y.-W., Yang, J.-Y., Ma, X., Chen, Z.-P., Hu, Y.-R., Zhao, J.-Y., et al. (2014). A lincRNA-DYNLRB2-2/GPR119/GLP-1R/ABCA1-dependent signal transduction pathway is essential for the regulation of cholesterol homeostasis. J. Lipid Res. 55, 681-697. doi:10.1194/jlr.M044669

Hu, Y.-W., Zhao, J.-Y., Li, S.-F., Huang, J.-L., Qiu, Y.-R., Ma, X., et al. (2015). RP5833A20.1/miR-382-5p/NFIA-dependent signal transduction pathway contributes to the regulation of cholesterol homeostasis and inflammatory reaction. Arterioscler. Thromb. Vasc. Biol. 35, 87-101. doi:10.1161/ATVBAHA. 114.304296

Huang, C., Hu, Y.-W., Zhao, J.-J., Ma, X., Zhang, Y., Guo, F.-X., et al. (2016). Long noncoding RNA HOXC-AS1 suppresses ox-LDL-induced cholesterol accumulation through promoting HOXC6 expression in THP-1 macrophages. DNA Cell Biol. 35, 722-729. doi:10.1089/dna.2016.3422

Huang, Z., Luo, Q., Yao, F., Qing, C., Ye, J., Deng, Y., et al. (2016). Identification of differentially expressed long non-coding RNAs in polarized macrophages. Sci. Rep. 6, 19705. doi:10.1038/srep19705

Huangfu, N., Xu, Z., Zheng, W., Wang, Y., Cheng, J., and Chen, X. (2018). LncRNA MALAT1 regulates oxLDL-induced CD36 expression via activating $\beta$-catenin. Biochem. Biophys. Res. Commun. 495, 2111-2117. doi:10.1016/j.bbrc.2017.12. 086

Hung, J., Scanlon, J. P., Mahmoud, A. D., Rodor, J., Ballantyne, M., Fontaine, M. A. C., et al. (2019). Novel plaque enriched long noncoding RNA in atherosclerotic macrophage regulation (PELATON). Arterioscler. Thromb. Vasc. Biol. 40, 697. doi:10.1161/ATVBAHA.119.313430

Indolfi, C., Iaconetti, C., Gareri, C., Polimeni, A., and De Rosa, S. (2019). Noncoding RNAs in vascular remodeling and restenosis. Vasc. Pharmacol. 114, 49-63. doi:10.1016/j.vph.2018.10.006

Johnson, J. L., and Newby, A. C. (2009). Macrophage heterogeneity in atherosclerotic plaques. Curr. Opin. Lipidol. 20, 370-378. doi:10.1097/MOL.0b013e3283309848

Kawai, T., and Akira, S. (2010). The role of pattern-recognition receptors in innate immunity: update on Toll-like receptors. Nat. Immunol. 11, 373-384. doi:10. 1038/ni.1863

Khallou-Laschet, J., Varthaman, A., Fornasa, G., Compain, C., Gaston, A.-T., Clement, M., et al. (2010). Macrophage plasticity in experimental atherosclerosis. PloS One 5, e8852. doi:10.1371/journal.pone.0008852

Koelwyn, G. J., Corr, E. M., Erbay, E., and Moore, K. J. (2018). Regulation of macrophage immunometabolism in atherosclerosis. Nat. Immunol. 19, 526-537. doi:10.1038/s41590-018-0113-3

Kruth, H. S., Jones, N. L., Huang, W., Zhao, B., Ishii, I., Chang, J., et al. (2005). Macropinocytosis is the endocytic pathway that mediates macrophage foam cell formation with native low density lipoprotein. J. Biol. Chem. 280, 2352-2360. doi:10.1074/jbc.M407167200

Kunjathoor, V. V., Febbraio, M., Podrez, E. A., Moore, K. J., Andersson, L., Koehn, S., et al. (2002). Scavenger receptors class A-I/II and CD36 are the principal receptors responsible for the uptake of modified low density lipoprotein leading to lipid loading in macrophages. J. Biol. Chem. 277, 49982-49988. doi:10.1074/ jbc.M209649200

Li, H., Han, S., Sun, Q., Yao, Y., Li, S., Yuan, C., et al. (2019). Long non-coding RNA CDKN2B-AS1 reduces inflammatory response and promotes cholesterol efflux in atherosclerosis by inhibiting ADAM10 expression. Aging (Albany NY) 11, 1695-1715. doi:10.18632/aging.101863

Li, X., Liu, R., Wang, Y., Zhu, W., Zhao, D., Wang, X., et al. (2020). Cholangiocytederived exosomal lncRNA H19 promotes macrophage activation and hepatic inflammation under cholestatic conditions, Cells 9, 190. doi:10.3390/ cells 9010190

Lin, H.-S., Gong, J.-N., Su, R., Chen, M.-T., Song, L., Shen, C., et al. (2014). miR199a-5p inhibits monocyte/macrophage differentiation by targeting the activin A type $1 \mathrm{~B}$ receptor gene and finally reducing C/EBPa expression. J. Leukoc. Biol. 96, 1023-1035. doi:10.1189/jlb.1A0514-240R

Liu, Y.-C., Zou, X.-B., Chai, Y.-F., and Yao, Y.-M. (2014). Macrophage polarization in inflammatory diseases. Int. J. Biol. Sci. 10, 520-529. doi:10.7150/ijbs.8879

Lu, J., Ji, H., Tang, H., and Xu, Z. (2018). microRNA-124a suppresses PHF19 overexpression, EZH2 hyper-activation, and aberrant cell proliferation in human glioma. Biochem. Biophys. Res. Commun. 503, 1610-1617. doi:10.1016/j.bbrc. 2018.07.089

Lu, W., He, X., Su, L., and Miao, J. (2019). Long noncoding RNA-CERNA1 stabilized atherosclerotic plaques in apolipoprotein E-/- mice. J. Cardiovasc. Trans. Res. 12, 425-434. doi:10.1007/s12265-019-09883-4

Lv, Y.-C., Tang, Y.-Y., Zhang, P., Wan, W., Yao, F., He, P.-P., et al. (2016). Histone methyltransferase enhancer of zeste homolog 2-mediated ABCA1 promoter 
DNA methylation contributes to the progression of atherosclerosis. PLoS One. 11, e0157265. doi:10.1371/journal.pone.0157265

Maguire, E. M., Pearce, S. W. A., and Xiao, Q. (2019). Foam cell formation: a new target for fighting atherosclerosis and cardiovascular disease. Vasc. Pharmacol. 112, 54-71. doi:10.1016/j.vph.2018.08.002

Maguire, E. M., and Xiao, Q. (2020). Noncoding RNAs in vascular smooth muscle cell function and neointimal hyperplasia. FEBS J. [Epub ahead of print] doi:10. $1111 /$ febs.15357

Mantovani, A., Sica, A., Sozzani, S., Allavena, P., Vecchi, A., and Locati, M. (2004). The chemokine system in diverse forms of macrophage activation and polarization. Trends Immunol. 25, 677-686. doi:10.1016/j.it.2004.09.015

Mathy, N. W., and Chen, X.-M. (2017). Long non-coding RNAs (lncRNAs) and their transcriptional control of inflammatory responses. J. Biol. Chem. 292, 12375-12382. doi:10.1074/jbc.R116.760884

McHugh, C. A., Chen, C.-K., Chow, A., Surka, C. F., Tran, C., McDonel, P., et al. (2015). The Xist lncRNA interacts directly with SHARP to silence transcription through HDAC3. Nature 521, 232-236. doi:10.1038/nature14443

McLaren, J. E., Michael, D. R., Ashlin, T. G., and Ramji, D. P. (2011). Cytokines, macrophage lipid metabolism and foam cells: implications for cardiovascular disease therapy. Prog. Lipid Res. 50, 331-347. doi:10.1016/j.plipres.2011.04. 002

Melgarejo, E., Medina, M. Á., Sánchez-Jiménez, F., and Urdiales, J. L. (2009). Monocyte chemoattractant protein-1: a key mediator in inflammatory processes. Int. J. Biochem. Cell Biol. 41, 998-1001. doi:10.1016/j.biocel.2008. 07.018

Meng, X.-D., Yao, H.-H., Wang, L.-M., Yu, M., Shi, S., Yuan, Z.-X., et al. (2020). Knockdown of GAS5 inhibits atherosclerosis progression via reducing EZH2mediated ABCA1 transcription in ApoE(-/-) mice. Mol. Ther. Nucleic Acids 19, 84-96. doi:10.1016/j.omtn.2019.10.034

Mestas, J., and Ley, K. (2008). Monocyte-endothelial cell interactions in the development of atherosclerosis. Trends Cardiovasc. Med. 18, 228-232. doi:10.1016/j.tcm.2008.11.004

Miano, J. M., Firulli, A. B., Olson, E. N., Hara, P., Giachelli, C. M., and Schwartz, S. M. (1996). Restricted expression of homeobox genes distinguishes fetal from adult human smooth muscle cells. Proc. Natl. Acad. Sci. U.S.A. 93, 900-905. doi:10.1073/pnas.93.2.900

Mitchell, J. P., and Carmody, R. J. (2018). NF-kB and the transcriptional control of inflammation. Int. Rev. Cell Mol. Biol. 335, 41-84. doi:10.1016/bs.ircmb.2017. 07.007

Moore, K. J., and Freeman, M. W. (2006). Scavenger receptors in atherosclerosis: beyond lipid uptake. Arterioscler. Thromb. Vasc. Biol. 26, 1702-1711. doi:10. 1161/01.Atv.0000229218.97976.43

Moore, K. J., Sheedy, F. J., and Fisher, E. A. (2013). . Nat. Rev. Immunol. 13, 709-721. doi:10.1038/nri3520

Moore, K. J., and Tabas, I. (2011). Macrophages in the pathogenesis of atherosclerosis. Cell 145, 341-355. doi:10.1016/j.cell.2011.04.005

Nádró, B., Juhász, L., Szentpéteri, A., Páll, D., Paragh, G., and Harangi, M. (2018). The role of apolipoprotein $M$ and sphingosine 1-phosphate axis in the prevention of atherosclerosis]. Orv. Hetil. 159, 168-175. [in Hu]. doi:10. $1556 / 650.2018 .30980$

Ou, M., Li, X., Zhao, S., Cui, S., and Tu, J. (2020). Long non-coding RNA CDKN2BAS1 contributes to atherosclerotic plaque formation by forming RNA-DNA triplex in the CDKN2B promoter. EBioMedicine 55, 102694. doi:10.1016/j. ebiom.2020.102694

Panee, J. (2012). Monocyte chemoattractant protein 1 (MCP-1) in obesity and diabetes. Cytokine 60, 1-12. doi:10.1016/j.cyto.2012.06.018

Paulson, K. E., Zhu, S.-N., Chen, M., Nurmohamed, S., Jongstra-Bilen, J., and Cybulsky, M. I. (2010). Resident intimal dendritic cells accumulate lipid and contribute to the initiation of atherosclerosis. Circ. Res. 106, 383-390. doi:10. 1161/circresaha.109.210781

Perkins, N. D. (2007). Integrating cell-signalling pathways with NF-kB and IKK function. Nat. Rev. Mol. Cell Biol. 8, 49-62. doi:10.1038/nrm2083

Ponnusamy, M., Liu, N., Gong, R., Yan, H., and Zhuang, S. (2011). ERK pathway mediates P2X7 expression and cell death in renal interstitial fibroblasts exposed to necrotic renal epithelial cells. Am. J. Physiol. Ren. Physiol. 301, F650-F659. doi:10.1152/ajprenal.00215.2011

Qin, H., Wilson, C. A., Lee, S. J., Zhao, X., and Benveniste, E. N. (2005). LPS induces $\mathrm{CD} 40$ gene expression through the activation of NF- $\mathrm{KB}$ and STAT-1a in macrophages and microglia. Blood 106, 3114-3122. doi:10.1182/blood-200502-0759

Rahman, M. M., and McFadden, G. (2011). Modulation of NF-kB signalling by microbial pathogens. Nat. Rev. Microbiol. 9, 291-306. doi:10.1038/nrmicro2539

Reddy, M. A., Chen, Z., Park, J. T., Wang, M., Lanting, L., Zhang, Q., et al. (2014). Regulation of inflammatory phenotype in macrophages by a diabetes-induced long noncoding RNA. Diabetes 63, 4249-4261. doi:10.2337/db14-0298

Sallam, T., Jones, M., Thomas, B. J., Wu, X., Gilliland, T., Qian, K., et al. (2018). Transcriptional regulation of macrophage cholesterol efflux and atherogenesis by a long noncoding RNA. Nat. Med. 24, 304-312. doi:10.1038/nm.4479

Shapouri-Moghaddam, A., Mohammadian, S., Vazini, H., Taghadosi, M., Esmaeili, S.-A., Mardani, F., et al. (2018). Macrophage plasticity, polarization, and function in health and disease. J. Cell. Physiol. 233, 6425-6440. doi:10.1002/jcp.26429

Shen, H., Sheng, L., Chen, Z., Jiang, L., Su, H., Yin, L., et al. (2014). Mouse hepatocyte overexpression of NF- $\mathrm{kB}$-inducing kinase (NIK) triggers fatal macrophage-dependent liver injury and fibrosis. Hepatology 60, 2065-2076. doi:10.1002/hep.27348

Shi, J., Gao, W., and Shao, F. (2017). Pyroptosis: gasdermin-mediated programmed necrotic cell death. Trends Biochem. Sci. 42, 245-254. doi:10.1016/j.tibs.2016.10.004

Shi, X., Liu, Z., Feng, X., Hua, F., Hu, X., et al. (2018). Long noncoding RNA PCAT6 functions as an oncogene by binding to EZH2 and suppressing LATS2 in nonsmall-cell lung cancer. EBioMedicine 37, 177-187. doi:10.1016/j.ebiom.2018.10. 004

Skaug, B., Jiang, X., and Chen, Z. J. (2009). The role of ubiquitin in NF-кB regulatory pathways. Annu. Rev. Biochem. 78, 769-796. doi:10.1146/annurev. biochem.78.070907.102750

Stefulj, J., Panzenboeck, U., Becker, T., Hirschmugl, B., Schweinzer, C., Lang, I., et al. (2009). Human endothelial cells of the placental barrier efficiently deliver cholesterol to the fetal circulation via ABCA1 and ABCG1. Circ. Res. 104, 600-608. doi:10.1161/circresaha.108.185066

Sun, C., Fu, Y., Gu, X., Xi, X., Peng, X., Wang, C., et al. (2020). Macrophageenriched IncRNA RAPIA: a novel therapeutic target for atherosclerosis. Arterioscler. Thromb. Vasc. Biol. 40, 1464-1478. doi:10.1161/ATVBAHA. 119.313749

Sun, D., Yu, Z., Fang, X., Liu, M., Pu, Y., Shao, Q., et al. (2017). Lnc RNA GAS 5 inhibits microglial M2 polarization and exacerbates demyelination. EMBO Rep. 18, 1801-1816. doi:10.15252/embr.201643668

Sunami, Y., Leithäuser, F., Gul, S., Fiedler, K., Güldiken, N., Espenlaub, S., et al. (2012). Hepatic activation of IKK/NFKB signaling induces liver fibrosis via macrophage-mediated chronic inflammation. Hepatology 56, 1117-1128. doi:10.1002/hep.25711

Tabas, I. (2010). Macrophage death and defective inflammation resolution in atherosclerosis. Nat. Rev. Immunol. 10, 36-46. doi:10.1038/nri2675

Tabas, I., and Bornfeldt, K. E. (2016). Macrophage phenotype and function in different stages of atherosclerosis. Circ. Res. 118, 653-667. doi:10.1161/ circresaha.115.306256

Tabas, I., Li, Y., Brocia, R. W., Xu, S. W., Swenson, T. L., and Williams, K. J. (1993). Lipoprotein lipase and sphingomyelinase synergistically enhance the association of atherogenic lipoproteins with smooth muscle cells and extracellular matrix. A possible mechanism for low density lipoprotein and lipoprotein(a) retention and macrophage foam cell formation. J. Biol. Chem. 268, 20419-20432.

Tang, X., Yin, R., Shi, H., Wang, X., Shen, D., Wang, X., et al. (2020). LncRNA ZFAS1 confers inflammatory responses and reduces cholesterol efflux in atherosclerosis through regulating miR-654-3p-ADAM10/RAB22A axis. Int. J. Cardiol. 315, 72-80. doi:10.1016/j.ijcard.2020.03.056

Taniguchi, K., and Karin, M. (2018). NF- $\mathrm{kB}$, inflammation, immunity and cancer: coming of age. Nat. Rev. Immunol. 18, 309-324. doi:10.1038/nri.2017.142

Tarhda, Z., Semlali, O., Kettani, A., Moussa, A., Abumrad, N. A., and Ibrahimi, A. (2013). Three dimensional structure prediction of fatty acid binding site on human transmembrane receptor CD36. Bioinf. Biol. Insights 7, 369-373. doi:10. 4137/bbi.S12276

Tichon, A., Gil, N., Lubelsky, Y., Havkin Solomon, T., Lemze, D., Itzkovitz, S., et al. (2016). A conserved abundant cytoplasmic long noncoding RNA modulates repression by pumilio proteins in human cells. Nat. Commun. 7, 12209. doi:10. 1038/ncomms12209

van der Vorst, E., Weber, C., and Donners, M. (2018). A disintegrin and metalloproteases (ADAMs) in cardiovascular, metabolic and inflammatory 
diseases: aspects for theranostic approaches. Thromb. Haemostasis 118, 1167-1175. doi:10.1055/s-0038-1660479

Verreck, F. A. W., de Boer, T., Langenberg, D. M. L., Hoeve, M. A., Kramer, M., Vaisberg, E., et al. (2004). Human IL-23-producing type 1 macrophages promote but IL-10-producing type 2 macrophages subvert immunity to (myco)bacteria. Proc. Natl. Acad. Sci. U.S.A. 101, 4560-4565. doi:10.1073/ pnas.0400983101

Virmani, R., Burke, A. P., Kolodgie, F. D., and Farb, A. (2002). Vulnerable plaque: the pathology of unstable coronary lesions. J. Intervent. Cardiol. 15, 439-446. doi:10.1111/j.1540-8183.2002.tb01087.x

Wang, J., Cao, B., Han, D., Sun, M., and Feng, J. (2017). Long non-coding RNA H19 induces cerebral ischemia reperfusion injury via activation of autophagy. A\&D 8, 71-84. doi:10.14336/ad.2016.0530

Wang, K. C., and Chang, H. Y. (2011). Molecular mechanisms of long noncoding RNAs. Mol. Cell 43, 904-914. doi:10.1016/j.molcel.2011.08.018

Wang, L., Xia, J.-W., Ke, Z.-P., and Zhang, B.-H. (2019). Blockade of NEAT1 represses inflammation response and lipid uptake via modulating miR-342-3p in human macrophages THP-1 cells. J. Cell. Physiol. 234, 5319-5326. doi:10.1002/jcp.27340

Wang, L. X., Zhang, S. X., Wu, H. J., Rong, X. I., and Guo, J. (2019). M2b macrophage polarization and its roles in diseases. J. Leukoc. Biol. 106, 345-358. doi:10.1002/JLB.3RU1018-378RR

Williams, K. J., and Tabas, I. (1995). The response-to-retention hypothesis of early atherogenesis. Arterioscler. Thromb. Vasc. Biol. 15, 551-561. doi:10.1161/01.atv.15.5.551

Wu, G., Cai, J., Han, Y., Chen, J., Huang, Z.-P., Chen, C., et al. (2014). LincRNAp21 regulates neointima formation, vascular smooth muscle cell proliferation, apoptosis, and atherosclerosis by enhancing p53 activity. Circulation 130, 1452-1465. doi:10.1161/CIRCULATIONAHA.114.011675

Wu, H., Wen, F., Jiang, M., Liu, Q., and Nie, Y. (2018). LncRNA uc.48+ is involved in the diabetic immune and inflammatory responses mediated by P2X7 receptor in RAW264.7 macrophages. Int. J. Mol. Med. 42, 1152-1160. doi:10.3892/ijmm.2018.3661

Xie, J., Li, Q., Zhu, X.-h., Gao, Y., and Zhao, W.-h. (2019). IGF2BP1 promotes LPSinduced NFKB activation and pro-inflammatory cytokines production in human macrophages and monocytes. Biochem. Biophys. Res. Commun. 513, 820-826. doi:10.1016/j.bbrc.2019.03.206

Xie, Y., Wang, M., Tian, J., Li, X., Yang, M., Zhang, K., et al. (2019). Long noncoding RNA expressed in macrophage co-varies with the inflammatory phenotype during macrophage development and polarization. J. Cell Mol. Med. 23, 6530-6542. doi:10.1111/jcmm.14557

Xie, Z., Zhang, H., Wang, J., Li, Z., Qiu, C., and Sun, K. (2019). LIN28B-AS1IGF2BP1 association is required for LPS-induced NFkB activation and proinflammatory responses in human macrophages and monocytes. Biochem. Biophys. Res. Commun. 519, 525-532. doi:10.1016/j.bbrc.2019.09.012

$\mathrm{Xu}$, Y.-J., Zheng, L., Hu, Y.-W., and Wang, Q. (2018). Pyroptosis and its relationship to atherosclerosis. Clin. Chim. Acta 476, 28-37. doi:10.1016/j. cca.2017.11.005
Yang, L., and Li, T. (2020). LncRNA TUG1 regulates ApoM to promote atherosclerosis progression through miR-92a/FXR1 axis. J. Cell Mol. Med. 24, 8836. doi:10.1111/jcmm.15521

Yap, K., Mukhina, S., Zhang, G., Tan, J. S. C., Ong, H. S., and Makeyev, E. V. (2018). A short tandem repeat-enriched RNA assembles a nuclear compartment to control alternative splicing and promote cell survival. Mol. Cell 72, 525-540.e13. doi:10.1016/j.molcel.2018.08.041

Ye, J., Wang, C., Wang, D., and Yuan, H. (2018). LncRBA GSA5, up-regulated by ox-LDL, aggravates inflammatory response and MMP expression in THP-1 macrophages by acting like a sponge for miR-221. Exp. Cell Res. 369, 348-355. doi:10.1016/j.yexcr.2018.05.039

Yin, Q., Wu, A., and Liu, M. (2017). Plasma Long Non-Coding RNA (lncRNA) GAS5 is a New Biomarker for Coronary Artery Disease. Med. Sci. Monit. 23, 6042-6048. doi:10.12659/msm.907118

Yong, H., Hong, Q., Xing, P., Yigang, F., Hongyan, T., and Jie, G. (2018). Low-dose sinapic acid abates the pyroptosis of macrophages by downregulation of IncRNAMALAT1 in rats with diabetic atherosclerosis. J. Cardiovasc. Pharmacol. 71 104-112.

Yu, B.-y., and Dong, B. (2018). LncRNA H19 regulates cardiomyocyte apoptosis and acute myocardial infarction by targeting miR-29b. Int. J. Cardiol. 271, 25. doi:10.1016/j.ijcard.2018.04.108

Zanin, R. F., Bergamin, L. S., Morrone, F. B., Coutinho-Silva, R., de Souza Wyse, A. T., and Battastini, A. M. O. (2015). Pathological concentrations of homocysteine increases IL-1 $\beta$ production in macrophages in a P2X7, NF-KB, and erk-dependent manner. Purinergic Signal. 11, 463-470. doi:10.1007/s11302-015-9464-5

Zeng, Y., Ren, K., Zhu, X., Zheng, Z., and Yi, G. (2018). Long noncoding RNAs: advances in lipid metabolism. Adv. Clin. Chem. 87, 1-36. doi:10.1016/bs.acc. 2018.07.001

Zhang, D.-D., Wang, W.-T., Xiong, J., Xie, X.-M., Cui, S.-S., Zhao, Z.-G., et al. (2017). Long noncoding RNA LINC00305 promotes inflammation by activating the AHRR-NF- $\mathrm{KB}$ pathway in human monocytes. Sci. Rep. 7, 46204. doi:10.1038/srep46204

Zhao, G., Su, Z., Song, D., Mao, Y., and Mao, X. (2016). The long noncoding RNA MALAT1 regulates the lipopolysaccharide-induced inflammatory response through its interaction with NF-KB. FEBS Lett. 590, 2884-2895. doi:10.1002/ $1873-3468.12315$

Conflict of Interest: The authors declare that the research was conducted in the absence of any commercial or financial relationships that could be construed as a potential conflict of interest.

Copyright $\odot 2020 \mathrm{Ma}$, Liu and Chen.. This is an open-access article distributed under the terms of the Creative Commons Attribution License (CC BY). The use, distribution or reproduction in other forums is permitted, provided the original author(s) and the copyright owner(s) are credited and that the original publication in this journal is cited, in accordance with accepted academic practice. No use, distribution or reproduction is permitted which does not comply with these terms. 